\title{
Diálogo inimaginável sobre a catástrofe brasileira: sátira literária
}

\section{Unimaginable dialogue about the Brazilian catastrophe: literary satire}

\author{
Ricardo Lísias* \\ rlisias@yahoo.com.br \\ Gabriel Nascimento** \\ gabrielnascimento@folha.com.br \\ Joanim Pepperoni, PhD ${ }^{* * *}$ \\ joanimpepperoni@gmail.com \\ Messias Botnaro ${ }^{\star \star \star \star}$ \\ messias.botnaro@protonmail.com
}

\section{Apresentação}

Neste diálogo inimaginável, colocamos frente a frente o escritor Ricardo Lísias, o editor Gabriel Nascimento e dois nomes emergentes na literatura brasileira contemporânea que publicam suas obras sob pseudônimo, como forma de ocultarem seus ortônimos: Messias Botnaro e Joanim Pepperoni, PhD.

Ricardo Lísias, há mais tempo na cena literária, estreou em 1999, com Cobertor de estrelas, ao qual já se seguiram outros quinze livros, em sua maioria no campo do que se denomina autoficção - conceito problematizado pelo escritor. As obras de Lísias, apresentadas como intervenção na realidade e confronto ao establishment, já geraram controvérsias que extrapolaram o âmbito literário. Exemplar é o Diário da Cadeia, de Eduardo Cunha (Pseudônimo), alvo de ação na justiça conduzida pelos advogados do ex-deputado federal. Se não houvesse ingerência jurídica sobre o projeto, não saberíamos que Lísias foi o autor.

\footnotetext{
* Doutor em Literatura Brasileira pela Universidade de São Paulo, com pós-doutorado na Universidade Federal de São Paulo.

** Editor Associado da Cousa. Graduado em História e graduando em Biblioteconomia pela Universidade Federal do Espírito Santo.

*** Pseudônimo de um escritor que não deseja ser identificado. Alimentando a sátira de si mesmo, autointitula-se pesquisador na Escola de Estudos de Excelência da Terra da Cocanha.

**** Pseudônimo de um escritor que não deseja ser identificado, apresenta-se como o primeiro defunto autor vítima de Covid-19.
} 
Na noite do segundo turno da eleição presidencial de 2018, Ricardo Lísias iniciou um diário que planeja escrever até o fim do governo de Jair Messias Bolsonaro. Trata-se do livro Diário da catástrofe brasileira, que começou a ser publicado no final de 2018 na plataforma de autopublicação da Amazon, a Kindle Direct Publishing. O volume impresso, subintitulado ano I: O inimaginável foi eleito, foi lançado em julho de 2020 pela Editora Record.

O livro apresenta uma análise do material de campanha, oficial e extraoficial. Comenta sobre a operação Lava Jato, obras de arte contemporânea, literatura brasileira, literatura francesa, histórias em quadrinhos e analisa os principais eventos políticos entre 2018 e 2019. O estilo do texto alterna entre o registro memorial e o ensaio crítico-teórico, com muitas digressões, oscilando entre o humor e a melancolia, destacando-se a ausência de conjunções adversativas.

Joanim Pepperoni, por sua vez, apareceu por volta de 2008, em um blogue que manteve ativo por muitos anos e no qual publicava textos satíricos, poemas e montagens visuais. A sua estreia em livro aconteceu em 2013, com o título A fantástica máquina de ensacar berros: relatório de pesquisa. Durante anos, abordou de forma cômica aspectos culturais e históricos da Terra da Cocanha, termo que usa para designar a Região de Colonização Italiana no Rio Grande do Sul. Em 2020, publicou o seu décimo livro intitulado Nane Cainha \& Nane Hábil: rimance político, uma espécie de epopeia às avessas em que satiriza recentes fatos políticos ocorridos no município gaúcho de Caxias do Sul, denominado Polentawood. Também no mesmo ano, trouxe a público a obra Rapa da panela, em que dedica uma seção de paródias à política nacional, desde Michel Temer até as polêmicas governamentais a respeito da pandemia do coronavírus.

Messias Botnaro, prefaciador de Nane Cainha \& Nane Hábil, surgiu em março de 2020, e se diz defunto-autor de dois livros digitais publicados originalmente por editoras fictícias: Tuítes Póstumos de um Herói Nacional e A guerra da cloroquina contra o comunavírus chinês, reunidos no volume impresso Minha Luta, com ilustrações de Marcio Vaccari, apresentação de Ricardo Lísias e posfácio de Joanim Pepperoni.

A prosa de Botnaro, que emula e satiriza o discurso de ódio bolsonarista, é incompatível com os gêneros literários conhecidos: não é conto, crônica, romance ou ensaio. As narrativas, em formas de tuítes ou posts de Parler, não têm enredos sequenciais. Cada capítulo mostra-se desligado um do outro, além de deter estilo 
distinto em cada fragmento - descritivos, oníricos, especulativos, narrativos, chulos, eruditos, pornográficos ou agressivos.

O diálogo literário que apresentamos a seguir foi realizado por e-mail durante o mês de novembro de 2020, em um formato em que cada autor teve acesso parcial às respostas dos outros entrevistados e pode fazer réplicas e tréplicas. Embora o tom desejado da matéria fosse, inicialmente, o acadêmico, de acordo com os princípios internacionais de conduta e prática editorial, os escritores enveredaram pelos caminhos da galhofa e do humor, de modo que o texto final embaralha as fronteiras entre ficção e realidade, assumindo contornos de sátira literária.

João Claudio Arendt e Vitor Cei

Editores convidados

Botnaro - Aviso que não vou responder a indagações descontextualizadas que revelam má fé e parcialidade. E não adianta vir com choro dissimulado e lábia de crocodilo. A língua é fascista porque o fascismo não consiste em impedir de dizer, mas em obrigar a dizer. Fascistas serão todos vocês que quiserem me obrigar a responder alguma pergunta. E digo mais: estou sabendo que o meu editor, Saulo Ribeiro, está conspirando com o Germano Quaresma e os economistas de esquerda, que caem sozinhos feito um pênis assolado pela blenorragia. Vocês estão espalhando por aí que a minha corrente filosófica é um escrotismo. Escrotismo é atributo dos comunistas que colecionam castelos de vento, ejaculação pífia de libertinos cansados, tá ok? E nem adianta chamar o Cristiano Machado Amoroso para me espancar. Parto para cima dele em chamas. Já estou morto.

Pepperoni - Não sei o que estou fazendo nesta conversa insana com um excretordefunto, que plagia descaradamente tuítes do abominável Biroliro, e um outro, de ego inflado, que só escreve sobre si mesmo, como se a sua insignificante vida pessoal importasse aos outros. Não quero participar dessa conversa. Como se sai desse grupo de Zap?

Arendt - Calma, Pepperoni... Estamos reunindo material sobre escritores contemporâneos para publicar em uma revista acadêmica. Você é um best-seller regional 
e merece constar nessa listagem de autores. Apenas responda a algumas perguntas e, em seguida, eu te excluo do grupo.

Pepperoni - Certo... Mas não me faça perguntas impertinentes, porque tenho uma reputação pra zelar. Aqui em Polentawood sobrenome é tudo: abre portas para negócios, almoços em família e fiado no armazém.

Botnaro - Joanim, primeiro eu quero tirar uma satisfação. Você não tem crédito para acusar ninguém, não tem credibilidade. Seu livro Rapa da Panela deturpa o tempo todo. Mente descaradamente. Trabalha contra a democracia. Eu quero ver quando você vai desfazer a covardia que fez contra o excelentíssimo Michael Tremer, chefe da minha missão humanitária no Líbano. Você o xingou de abominoso Vampiro e raposa velha. Me chamou de Biroliro, me xingou de parasita inconteste. Você queria um furo, queria dar o furo a qualquer preço contra mim. Atitudes como essa devem ser totalmente repudiadas.

Cei - Por que vocês escrevem?

Lísias - Escrevo para dar vazão a uma série de necessidades, algumas íntimas e outras públicas. Quanto às últimas, entre elas estão um gosto por invenção e outro por intervenção. Então acho que consigo unir as duas coisas escrevendo. Também gosto de observar discursos, ideologias e estranhamentos. Por fim, aos poucos é o que acabou se tornando a minha principal atividade.

Botnaro - Escrevo porque o Brasil tem que deixar de ser um país de maricas. Temos que enfrentar os desafios de peito aberto, lutar. Encaro a escrita como ato político diferente. Ato político não é só sair por aí com bandeiras ou metralhadoras. Escrevo para possibilitar uma reorientação positiva e construtiva dos brasileiros patriotas ante as ameaças do comunismo, do gayzismo, do globalismo e do satanismo. Escrevo para trapacear a língua, porque é no interior da língua que a língua deve ser combatida. Minha obra reunida concilia o combate ao esquerdismo com a necessidade do cultivo de uma elevada espiritualidade, para a plena realização do amplo projeto filosófico de Orvalho de Farfalho, o filósofo dos filósofos. Minha Luta almeja um resgate da autoridade normativa dos valores, enquanto uma condição necessária para o 
fortalecimento do presente e de um revigoramento do futuro. Este dossiê prova que estou conseguindo o que pretendi, ou seja, chamar atenção para o meu trabalho, que tem ganhado notoriedade diante da crítica especializada. Quem quiser saber mais pode comprar a minha Obra Reunida na editora Cousa.

Pepperoni - Eu escrevo porque a caneta existe / E a caderneta está aberta / Não sou Bozo nem sou Trump / Sou poeta.

Nascimento - Botnaro, contar-nos sua trajetória em forma de livro não deixa de ser uma surpresa. Dentre todas as possibilidades de expressão que estão disponíveis, qual a razão da escolha pelo livro e não por um vídeo do YouTube, Tiktok, Instagram?

Botnaro - Gabriel, o motivo é óbvio. Eu não tenho um corpo físico. Eu até poderia ter testado os experimentos físicos/metafísicos de Friedrich Jurgenson e Ernst Senkowski, de Transcomunicação Instrumental, captação de vozes dos mortos, para fazer um podcast. Mas não se justifica um bilionário aporte financeiro numa tecnologia que sequer ultrapassou sua fase de testagem. Como eu sou conservador, optei pela tradicional psicografia mecânica, que funciona desde o século XIX.

Cei - Qual é o lugar de fala de vocês?

Lísias - O pior possível: um homem branco, de classe média alta, heterossexual e cisgênero. Então, tenho que me revoltar.

Pepperoni - Eu falo desde o $4^{\circ}$ andar do Observatório Colonial, em Polentawood. Daqui eu observo a vida política e cultural dos cocanheses e a transformo em poemas, narrativas e peças teatrais. Antes da pandemia, que me obrigou ao isolamento social, eu costumava fazer longas viagens para escavar sítios antropolentológicos. Pra você ter uma ideia, fui eu que encontrei o fóssil do Luomo Polentus, que é o elo perdido entre os cocanheses e seus ancestrais paphlagônicos. Quando acabar a pandemia, quero fazer uma profunda e extensa pesquisa sobre a família Birolirus, em Glicerina, Som Paulo. A minha hipótese é a de que o Bozo Biroliro tomava o café adulterado pela famiglia e comia basicamente polenta sem molho. Vou recolher amostras de fezes e restos de comida na casa em que nasceu, para provar que essa pobre dieta 
alimentar provocou nele a pelagra, também conhecida como Polenta 3D, cujos sintomas são diarreia, dermatite e demência. Dali vou seguir o rastro do demente até um condomínio em Arroio Genaro e, depois, até um aviário de emas em Brasmilha.

Botnaro - A geração hoje em dia é Toddynho, Nutella. Já vem uma turminha falar: "Queremos um de centro, nem ódio para lá, nem ódio para cá". Ódio é coisa de marica, pô. No meu tempo, bullying na escola era porrada. Agora, se chamar o cara de gordo é bullying. Essa conversa esquerdista de lugar de fala é uma folha ao vento, um brinquedo do absurdo, do sem-sentido, sintoma de dispepsia mental, resultado de um profundo descrédito dos valores dominantes no Ocidente. Talvez os meus seguidores sofram demais as consequências dessa ideologia - essas consequências para mim não são, ao contrário do que talvez se esperasse, de modo algum incômodas, mas sim algo desprezíveis. Eu sou a moral mesma, e nada além é moral. Eu sou o senhor do livre-arbítrio, detentor de uma vontade própria, duradoura e independente. Eu posso manter minha palavra contra o que é adverso, mesmo contra o destino (superei até mesmo a morte). Nós temos que buscar mudanças. Não teremos outra oportunidade.

Nascimento - Botnaro, podemos ver pelos seus escritos que o senhor é muito grato à morte. Já em vida, falava muito dela. Como a morte mudou sua maneira de ver a vida? Há algo que o senhor mudaria em sua trajetória pessoal, ou algum erro que agora, do outro lado, reconheça?

Botnaro - Gabriel, você tem que ser muito cara de pau para perguntar como a morte mudou a minha maneira de ver a vida. Porra, você não leu meu livro? Editou sem ler? Tá escrito lá na página 24: eu expliquei que a morte me preparou para a filosofia. Se em vida eu cultivava desprezo pelo conhecimento e reduzia as atividades intelectuais ao mínimo necessário, a morte revelou o sentido verdadeiro das coisas. Considerando que o Ricardo também me perguntou sobre erros, respondo em seguida.

Lísias - Dado o fato de o senhor estar no inferno, podemos considerar que deu tudo errado, presidente? 
Botnaro - É a vida, Ricardo. Você e o Gabriel também vão morrer um dia. Os idosos são considerados o primeiro grupo de risco da doença. De acordo com dados do Ministério da Saúde, pessoas com mais de 60 anos correspondem a $69 \%$ das mortes por Covid-19, descontadas as subnotificações. É bom que as mortes se concentrem entre os idosos. Isso melhorará nosso desempenho econômico, pois reduzirá nosso déficit previdenciário. Além disso, a desigualdade social é um fator agravante, uma vez que a população mais pobre é a mais suscetível aos impactos da nova pandemia. Portanto, a estratégia do meu governo em relação ao Covid-19 não foi prejudicada em nenhum momento. Quanto menos pobres e idosos, melhor para a economia. Meu governo, de forma arrojada, implementou várias medidas econômicas que evitaram o mal maior. Mesmo assim a escória esquerdista investe novamente na narrativa que desemprego e 160 mil mortos seriam culpa do Presidente, e não de governadores e Prefeitos, como se o Governo Federal não tivesse investido bilhões para o bem estar do Brasileiro. O jogo é claro!

Lísias - Prezado, a minha pergunta não se referia ao senhor ter morrido e sim a um fato posterior: depois de morrer, o senhor foi para o inferno... Como bom cristão, o senhor bem sabe que esse é o destino daqueles que não foram exatamente bons cristãos por aqui. Assim, repito com mais clareza: o que o senhor fez para ir parar no inferno?

Botnaro - Estimado Ricardo, em uma análise estruturalista, o espaço das minhas narrativas seria considerado esvaziado, por não haver elementos que descrevam o espaço onde me encontro. Eu nunca escrevi que estou no inferno. Essa é uma fake news que você espalhou na apresentação da minha Obra Reunida. Eu disse, na Advertência de Tuítes póstumos de um herói nacional, que eu vivo no reino escuro. $\mathrm{O}$ primeiro a me receber aqui no meu atual endereço residencial foi o Príncipe Hamlet. Ele chamou isso aqui de "undiscover'd country". Você pode chamar de eterno país misterioso, terra obscura de onde ninguém voltou ou país desconhecido de onde nenhum viajante retorna. Inferno é o lugar para onde os comunistas querem nos levar, usando o comunavírus como escada.

Lísias - Botnaro, agradeço os esclarecimentos, mas sejamos diretos: por que eu deveria me basear no que você diz? A gente percebe no entorno da sua obra o 
enxofre, no meio de tudo o que lemos está o Coisa Ruim. Então, não vejo por que motivo chamar de qualquer outro nome. De toda forma, o céu cristão não é um "undiscover'd country". Portanto as coisas deram errado para você. Quero saber se você admite isso e sabe localizar seus erros. Agradeço a resposta.

Botnaro - Ricardo, não é por aí, reconheço as suas qualidades, mas não me chama de mentiroso. Senão esse troca-troca não vai dar certo. Eu sempre abri o coração para você, mas duvido que você tenha aberto o coração para mim. A confiança tem que ter dupla mão. E outra coisa, é desmoralizante para um presidente ouvir isso, mais ainda, externar. A mídia, outras instituições, já me botaram de cabeça para baixo, chacoalharam tudo. Não encontraram nada. Admito que teve uma falha nossa. Falha minha, né. Quando eu convidei o Sérgio Bobo para ser meu paladino da justiça. Uma coisa é você admirar uma pessoa. A outra, é conviver com ela, trabalhar com ela. Torci muito pra dar certo. Muito. Mas, infelizmente, ou felizmente, eu tive quase que exigir e implorar a Sergio Bobo que apure quem mandou me matar a facadas. A Polícia Federal de Sergio Bobo se preocupou mais com a Marielle do que com seu chefe supremo. Cobrei muito dele isso aí. Eu fiquei triste porque ele era um ídolo pra mim. Estou decepcionado e surpreso com o comportamento dele. Sempre dei plena liberdade aos meus ministros, sem abrir mão do meu poder de veto e da minha autoridade como presidente da República. O Brasil é maior do que qualquer um de nós. Esse é o nosso compromisso. Esse é o nosso dever de servir à pátria. A pátria vai ter, de cada um de nós, o seu empenho, o seu sacrifício e se possível, se for necessário, o meu sangue para defender a democracia e a liberdade. Eu morri pela pátria. Eu desliguei o aquecedor da piscina olímpica do Alvorada, modificamos o cardápio, mas isso não tem nada a ver. É obrigação da minha parte. Isso é só para lembrar que eu tenho preocupação com a coisa pública e busco dar o exemplo.

Lísias - Botnaro, a sua prolixidade me espanta um pouco e parece ser proposital, para me confundir. Continuarei caminhando lentamente, até porque você não vai me levar junto... De resto, eu jamais me engajaria, por assim dizer, em um troca troca com uma pessoa como o senhor e menos ainda com uma assombração. Dessa forma, eu preciso partir do que tenho de mais seguro: o senhor não existe no meu mundo. Já foi. É a partir desse ponto que eu começo a pensar. O senhor já admitiu que um dos 
erros foi nomear o Sergio Moro. Enfim, poderia elencar outros erros? Posso dar uma ajuda: o que o senhor me diz de sua nomeação do ex-ministro L. H. Mandetta?

Botnaro - Pô, nós tivemos um médico no Ministério da Saúde, o Manetta, e olha a desgraça que foi. Ele foi contratado para privatizar o SUS, mas no meio do caminho tinha uma pandemia, tinha uma pandemia no meio do caminho. No meio do caminho tinha uma pandemia. Nunca me esquecerei desse acontecimento na minha vida pósmorte. Nunca me esquecerei que a extrema imprensa brasileira e o Manetta politizaram o vírus, disseminando o pânico entre a população. Sob o lema "fique em casa" e "a economia a gente vê depois", quase trouxeram o caos social ao país. A linha do Manetta era voltada quase que exclusivamente para a defesa da vida. No entanto, nós sabemos que as consequências de uma economia desajustada também levam à morte. O Brasil não pode parar!

Nascimento - Há algo de interessante em seu livro, ainda sobre a vida sobrenatural, que é o fato de o Deus cristão não ter aparecido como esperávamos. Isso te frustrou? Apesar disso, ainda defende ser terrivelmente cristão para os viventes?

Botnaro - Você está me acusando de plagiar aquele homem louco que acendeu uma lanterna e correu ao mercado para anunciar a morte de Deus? Aqui no reino escuro, nós vagamos através de um nada infinito e sentimos anoitecer eternamente... É claro que o Deus cristão não poderia aparecer como você esperava. Em primeiro lugar, não posso adivinhar o que você esperava, porque representações mentais de Deus têm um caráter único e imutável. Em segundo lugar, eu disse no meu livro que cá no outro mundo nenhuma divindade aos olhos surge, porque eu não posso representar o irrepresentável, o inefável. A humildade tem que se fazer presente entre nós. Eu era do baixíssimo clero, vocês sabem disso. Eu era uma carta fora do baralho no maior nível político do Brasil naquela época. Resolvi me candidatar tendo Deus e a verdade acima de tudo. Chegamos. Eu não sou a pessoa mais importante do Brasil, assim como Dump não é a pessoa mais importante do mundo, como ele bem disse. A pessoa mais importante é Deus. E eu fui ungido por Deus para liderar o Brasil. Eu sou a pedra desprezada pelos esquerdistas, eu sou a pedra angular. De fato, a pedra que os órgãos de imprensa rejeitaram, que a mídia rejeitou, a pedra que os intelectuais rejeitaram, a pedra que tantos artistas rejeitaram, a pedra que tantos autoproclamados 
especialistas rejeitaram, essa pedra tornou-se a pedra angular do edifício, o edifício do novo Brasil. O Brasil é um país majoritariamente cristão e a esquerda tenta proibir símbolos religiosos de qualquer espécie, inclusive dentro do gabinete de políticos. Tais propostas não logram êxito, mas insistem sempre que possível. Até quando vamos tolerar o ódio assassino que a indústria da mídia volta contra o cristianismo? Falta quanto para vocês perceberem que parte de movimentos sociais e parte da imprensa estão numa cruzada contra os cristãos? Na ONU, denunciei a existência da grande perseguição aos cristãos ao redor do mundo: a cristofobia. Recentemente igrejas foram incendiadas na capital do Chile por grupos de esquerda. Não é "somente" um ato terrorista. Não é "só" Cristofobia. É uma tentativa de destruir as bases da civilização ocidental. O objetivo deles parece cada dia mais claro: destruição e morte. Alguma dúvida de quanto o comunismo odeia a fé Cristã?

Nascimento - Botnaro, ainda sobre o tema da morte, uma íntima companheira que o senhor acolheu, como é desejar essa mesma experiência para seus inimigos se contigo foi algo tão benéfico?

Botnaro - Gabriel, vamos conversar sobre isso lá na ponta da praia. Você sabe que os comunistas são assassinos por natureza e vocação. Eu não desejo a morte para os meus piores inimigos. Na intimidade, até pai fala que vai matar filho, namorado fala que vai matar namorada. Mas eu sou favorável à tortura, você sabe disso. O povo é favorável também. E a gente lamenta todos os mortos, mas é o destino de todo mundo. Paciência, acontece, e vamos tocar o barco.

Nascimento - Existe diferença entre morte e sofrimento? Você sofreu ao morrer? Foi um processo de agonia?

Botnaro - Em essência, toda vida é sofrimento. A morte não é triste nem alegre. Mais não digo, porque o portador da luz não me autorizou. É simples assim: um manda e o outro obedece. Conseguintemente, evito contar o processo extraordinário de mudança para o meu atual endereço residencial. Seria curioso, mas nimiamente extenso, e aliás desnecessário ao entendimento da obra. 
Nascimento - Botnaro, estar no outro mundo é um momento, como o senhor mesmo fala, de grandes revelações e contatos com outros mortos e suas vozes. Como é o impacto de poder conhecer os guerrilheiros dos movimentos contra a ditadura do Brasil? E os intelectuais e revolucionários do mundo todo? E os nomes da direita e extrema direita? São como o senhor esperava?

Botnaro - Oh Gabriel, larga de frescura nessa questão. Já disse no meu livro que aqui não há sujeito, apenas agenciamentos coletivos de enunciação. Neste eterno país misterioso nós não somos prisioneiros de relações ideológicas. Ideologia não, ideias sim. Todos nós falamos a mesma língua, somos máquinas coletivas de expressão.

Botnaro - Ricardo, a chamada deste dossiê diz que a literatura brasileira hoje é marcada pelas escritas de si e por modos do retorno do autor, bem como por dinâmicas de apropriações e reformulações das diversas tradições. Os seus livros, que têm muita coisa escrita, seguem essa tendência.

Pepperoni - Ô criatura afásica da valeta, se você gosta de livro com pouca coisa escrita, vai ler as ejaculações poéticas do vampiro Tremer ou a fiofosia esquizofrênica do Ofalo de Gagalho. Eu tenho formação clássica e não economizo palavras para bem me expressar. Você ainda não tinha vindo a furo, quando eu escrevi, em coautoria com o Karl e o Fred, o aclamado Manifesto comunista que mudou a história da humanidade. Um magnífico livro, sem nenhuma figura, lido por todos os esquerdistas que você despreza!

Lísias - Não tenho nenhuma ideia de quem escreveu esse dossiê. Não li. Mas só pode ser coisa mesmo de necrófilo: não existe retorno do autor, não acredito em vida após a morte. E como o prezado Botnaro bem sabe, o autor morreu. Enfim, eu nunca prestei atenção para o fato de meus livros terem ou não muita coisa escrita, Botnaro. Só os releio em ocasiões muito especiais. Se tivessem poucas coisas escritas, enfim, não sei, achei a constatação estranha.

Botnaro - Ricardo, é claro que você não leu o dossiê, porque ele ainda não foi publicado. Mas voltando ao assunto: os personagens dos seus livros têm o seu nome. Entendo que o seu projeto literário não cabe no rótulo da autoficção, conceito que 
você recusa, satiriza e ironiza o tempo todo. Você tensiona o sujeito escritor, a instância autor e os personagens. Mas confessa para mim: é tudo narcisismo ou só está seguindo a moda literária?

Lísias - Não tenho nada para confessar e no geral não simpatizo nem com confessório e muito menos com confissões.

Botnaro - Quando você disse que a minha obra não é representação, que não é a reprodução, inexata ou precisa, do que vocês vivem, você se baseia em que entendimento? Minha obra promove uma ruptura com o sistema mimético de representação sensível ou o quê?

Lísias - Botnaro, de fato esse lugar desconhecido aí onde você foi parar não the favorece muito a cognição, que a propósito nunca foi o seu forte mesmo... Eu me baseio no meu entendimento, dado que quem entendeu isso fui eu... Suas perguntas são grandiloquentes, mas não permitem uma resposta minimamente razoável. Você não pode romper com o sistema mimético porque não faz parte dele. Trata-se de outra operação, que está longe da representação: a principal questão do seu trabalho é ele mesmo: de fato alguém fez isso, colocou isso para circular e esse estar no mundo produz algo. Para um morto talvez seja de fato meio difícil de entender.

Botnaro - Este troca-troca que estamos fazendo é bem incomum na literatura brasileira contemporânea. Estamos fazendo um verdadeiro crossover entre distintos universos, o que pode gerar efeitos positivos ou negativos na recepção de nossas obras. E será mais uma evidência da nossa disposição de dialogar criticamente. Ricardo e Joanim, como esta conversa inimaginável se insere em seus projetos literários? Podemos considerá-la uma extensão de suas obras?

Lísias - Botnaro, por que esse interesse em de repente parecer sério? Não vai funcionar, pois você sempre será ligado mais à figura do presidente da república terraplanista do que à dos que tentaram entender minimamente o que deu nesse país, ou em boa parte desse mundo. De toda forma, devo dizer que se do presidente eu tenho verdadeiro e recorrente asco, das suas coisas eu gosto! 
Pepperoni - Esta conversa já devia ter terminado, e o alemón já devia ter me excluído do grupo, como prometido. Isso aqui lembra a hora do recreio da quinta série, em que os bambini ficam se impuiando, se passando tranca e fazendo concurso de guspe. Logo, não acrescenta nada de produtivo ao currículo de um respeitado homem da Ciência e da Literatura como eu, indicado ao Prêmio Ignóbel 2021.

Pepperoni - Já que não posso sair do recreio da quinta série, quero fazer uma pergunta ao seu excelentíssimo senhor Messias Botnaro que, dizem, foi o primeiro escritor brasileiro a morrer por causa do Covid-19. A cloroquina e o ozônio na culatra não salvaram sua vida. Se já existisse vacina, vossa excrescência teria se vacinado?

Botnaro - Morte, invalidez, anomalia. Esta é a vacina que o Bolsodória queria obrigar a todos os paulistanos a tomar. Recentemente, a Anvisa suspendeu o Coronavac. Eu disse que a vacina jamais poderia ser obrigatória. Mais uma que Messias Botnaro ganha. Eu morri, mas minhas palavras continuarão ardendo nos seus cus por séculos. E como eu disse no meu livro, não tem como evitar a morte no tocante ao comunavírus, que foi fabricado em laboratório. Até o filósofo comunista Mauricio Abdalla denunciou a origem laboratorial do comunavírus chinês em matéria no jornal comunista Le Monde Diplomatique. Eu repudio qualquer tipo de iniciativa no sentido de obrigar cidadãos brasileiros a se vacinarem contra a própria vontade. Todos serão vacinados na marra? Acham que nossas famílias são frangos de granja? A vacina não será obrigatória. Ainda mais algo experimental, cujos testes não foram concluídos e cuja origem não é exatamente clara. Não concordo e lutarei contra atos nesse sentido. O povo brasileiro não será cobaia de ninguém. E mesmo que eu tenha morrido, o Brasil ainda será reconhecido pelo restante do mundo como um exemplo de combate ao comunavírus. Estou escrevendo a minha autobiografia, em que contarei com mais detalhes a minha guerra contra o comunavírus chinês. Aguardem o lançamento em 2022.

Botnaro - Joanim, um alemón bigodudo disse que sua Obra Reunida é um pagamento por sua longa, valente e laboriosa obra distribuída gratuitamente. Ele também disse que para se compreender a literatura do grande poeta-comediógrafo da Terra Cocanha é imprescindível ser quase uma vaca, e não um homem. Isso aí é verdade ou é fake news? 
Joanim - Vai de retro, capiroto! Tu vês conspiração em tudo! Procura um exorcista de esquina pra te desobsessar!... A minha obra é erudita, brilhante, de pensamentos novos, digna deste século e deste milênio. É um símbolo! E eu sempre a distribuí gratuitamente, porque acredito que a arte verdadeira deve estar a serviço da coletividade e não do mercado. Quem escreve livros para vender devia ser enforcado nas tripas de um porco capitalista. Todos os meus livros estão gratuitamente disponíveis para download no site www.academia.edu. E a Obra reunida é o tipo de edição impressa por demanda para quem deseja ter um exemplar físico para equilibrar a mesa de carnear porco. Nunca recebi um tostão de direito autoral. Então, para de achar que TU é a Constituição e não vem me cagar lei em cima!

Botnaro - Joanim, seu procedimento caricatural e paródico do ideal de grandeza e fortuna do homem cocanhês acaba por trazer consigo uma forte conotação de desengano; decepção pela frustração das expectativas de sexo, fartura, liberdade e eterna juventude. Quem esperava o dolce far niente, o prazer que não é preciso buscar porque ele apenas vem, acabou encontrando apenas comunismo, ditadura gay, vinho batizado, queijo vencido, embutido adulterado. Não é muita maldade sua achincalhar o sofrimento desse povo honrado, louro de olhos azuis, trabalhador, liberal na economia e conservador nos costumes?

Joanim - Capiroto, tu não entendeste nada do meu livro. Quem te passou informações pra me fazer essa pergunta deve ser mais stchopa sem munição do que tu. Eu não achincalho ninguém, apenas registro poeticamente tudo o que observo no dia a dia da Terra da Cocanha. Então, não me acusa de mexeriqueiro da cocanha alheia. Pede pra alguém com dois neurônios explicar ao teu assessor esta passagem da minha Obra reunida sobre a Terra da Cocanha: "Mas aqui não. Toda ficção tem ares de realidade - ou melhor, toda realidade tem ares de ficção. Assim, desde um simples alimento, até as cousas mais complexas do espírito, tudo assume dimensões de fábula e contornos de mito. A polenta, por exemplo, feita com apenas três ingredientes e cujo preparo é mais simples que uma lavagem para porcos, está cercada de ritos de toda ordem." Essa é a realidade sem nenhum exagero ou distorção. 
Nascimento - Botnaro, gostaríamos de saber como o senhor observa o resultado das eleições americanas e a relação delas com o Brasil. Com sua sabedoria desenvolvida, consegue enxergar como será o caminho que aguarda o futuro dos dois países?

Botnaro - O problema não é "Quem ganhou a eleição?". É "Quem cometeu o maior crime eleitoral de todos os tempos e o que a Justiça vai fazer com ele?" A FRAUDE é processo criminal, não eleitoral, PORRA! PORRA! PORRA! PORRA! PORRA! PORRA! PORRA! PORRA! PORRA! PORRA! PORRA! PORRA! PORRA! PORRA! PORRA! Acontece nos Estados Unidos, Acontece no Brasil! I love you, Dump!

Nascimento - Botnaro, para encerrarmos esta conversa, gostaria de te pedir, dentro de todo seu esclarecimento, palavras que resumam seus sentimentos em relação ao passado, ao presente e ao futuro, como um recado para todos os nossos leitores.

Botnaro - Meus sentimentos em relação ao passado, ao presente e ao futuro estão registrados em Minha Luta: obra reunida. Lá tem o máximo que os nossos leitores precisam saber para não ser idiotas. Adquira já seu exemplar na loja virtual da Editora Cousa. Também gostaria de agradecer a Saulo Ribeiro, Gabriel Nascimento, Marcio Vaccari, Leidijane Rolim e Luana Dias, que colaboraram na produção de Minha Luta. E também agradeço a Ricardo Lísias, Joanim Pepperoni, Eduardo Vicentini, Junia Zaidan, Rodrigo Casarin, Ronald Augusto e Vitor Cei, que escreveram os paratextos. Juntos temos como fazer o livro Minha Luta ocupar o lugar de destaque que ele merece no mundo e trazer prosperidade para a editora Cousa.

Joanim - Olha só a cara de pau dele de dizer que eu contribuí com um paratexto! Ele me foi pungado pelos capangas do Karl Luxo e do Flafluvio, quando fiz conexão no Rio de Janeiro há alguns meses. E ainda tem coragem de fazer autopromoção com esse livro repleto de crimes contra os direitos autorais?

Lísias - Botnaro, me desculpe a demora em responder. No caso de hoje, eu estava esperando passar a meia noite, pois você é um ser da madrugada; e no caso dos últimos dias, tive inúmeros problemas desde que começamos a dialogar. Você me deu azar. Observando todas as suas respostas, percebo que você se sobressai na maioria das vezes porque não fala coisa com coisa: não temos como responder porque não 
tem cabimento nenhum o que você diz: é só abjeção, culto à morte, linguagem histérica e falta de lastro na realidade. Lamento que o Brasil tenha dado confiança para um sujeito como você, Botnaro. Fico aliviado, por outro lado, que você já tenha ido e vade retro, cramulhão!

\section{Referências}

BOTNARO, M. Minha Luta: obra reunida. Vitória: Cousa, 2020.

BOTNARO, M. A guerra da cloroquina contra o comunavírus chinês. República dos Pampas, Estados Unidos do Sul: Parallel Brasilien Verlag, 2020. Disponível em: < https://mundodivague.academia.edu/MessiasBotnaro>. Acesso em: 01 dez. 2020.

BOTNARO, M. Tuítes póstumos de um herói nacional. Washington, D.C.: Alliance for Brazil Press, 2020. Disponível em: https://mundodivague.academia.edu/MessiasBotnaro>. Acesso em: 01 dez. 2020.

CUNHA, E. (Pseudônimo). Diário da cadeia-com trechos da obra inédita Impeachment. Rio de Janeiro: Record, 2017.

LíSIAS, R. Diário da catástrofe brasileira: ano I: o inimaginável foi eleito. Rio de Janeiro: Record, 2020.

LÍSIAS, R. Cobertor de estrelas. Rio de Janeiro: Rocco, 1999.

PEPPERONI, J. Obra reunida. Polentawood: Prensa de Torresmos Cantina do Frei; Joinville, SC: Clube de Autores, 2020. 